\title{
Tuzak nöropatilerde elektrofizyolojik incelemeler
}

\section{Electrophysiological examinations in entrapment neuropathies}

\author{
Çağrı Mesut Temuçin ${ }^{1}$, F. Gökçem Yıldız \\ ${ }^{1}$ Hacettepe Üniversitesi Tıp Fakültesi, Nöroloji Anabilim Dalı, Ankara \\ ${ }^{2}$ Hacettepe Üniversitesi Tıp Fakültesi, Nörolojik Bilimler ve Psikiyatri Enstitüsü, Ankara
}

Elektronöromiyografik incelemeler, tuzak nöropatilerin tanısı, ayırıcı tanısı ile cerrahi girişimlerin yönlendirilmesi ve takibinde önemli yer tutar. Elektronöromiyografi ile, sinir lezyonunun lokalizasyonu, hangi bölümlerinin etkilendiği, şiddeti ve zaman içindeki seyri konusunda objektif bilgiler elde edilir. Bu derlemede, elektronöromiyografi incelemesinde kullanılan duyu ve motor sinir iletim ve iğne elektromiyografi çalışmaları ile ilgili temel kavramlar özetlendikten sonra, alt ve üst ekstremite tuzak nöropatilerde gözlenen elektronöromiyografi bulguları gözden geçirilmektedir.

Anahtar sözcükler: elektronöromiyografi; duyusal ve motor nöropati; elektromiyografi, iğne; tuzak nöropatiler
Electroneuromyography is important in the diagnosis and differential diagnosis of the entrapment neuropathies as well as in planning and following up surgical procedures. Electroneuromyography provides objective data in determination of affected part of nerves, its severity and localization and time course of the lesions. In this review, after summarizing the basic concepts of sensory and motor conduction studies and needle electromyography examination, electroneuromyography findings in entrapment neuropathies will be discussed.

Key words: electroneuromyography; sensory and motor neuropathy; electromyography, needle; entrapment neuropathies

duyu sinirinin elektriksel olarak cilt üstünden uyarımını takiben, aynı sinirin anatomik seyri boyunca proksimal (ortodromik) veya distal (antidromik) bir noktasından, yine cilt üzerine yerleştirilen yüzeyel elektrodlar ile mikrovolt düzeylerindeki duyu siniri aksiyon potansiyeli (DSAP) kayıt edilir. Periferik motor bir sinirin benzer şekilde uyarımı ile de, aynı sinirin innerve ettiği bir kas üzerine yerleştirilen elektrodlarla, milivolt düzeylerinde birleşik kas aksiyon potansiyeli (BKAP) elde edilmektedir. DSAP ve BKAP'ların, uyarım sonrası kayıt elektrotlarına ulaşma zamanı olan latans ile genlikleri (amplitude) ölçülür. Duyu sinir iletim çalışmalarında, elektriksel uyarım ile kayıt elektrodu arasındaki mesafenin DSAP latansına bölünmesi ile, $\mathrm{m} / \mathrm{sn}$ cinsinden duyu sinir iletim hızları hesaplanabilmektedir. Duyu sinir iletim çalışmaları, rutin incelemeler sırasında, parmak-bilek, malleol-bilek gibi distal sinir bölümlerinde gerçekleştirilir. Motor sinirlerde ise BKAP kastan kaydedildiğinden, sinir-kas kavşağındaki asetilkolin aracılı kimyasal iletiminden kaynaklanan, ek bir gecikme vardır. Bu nedenle, sinir distal ve proksimal olmak üzere iki farklı bölgeden uyarılarak, distal ve proksimal BKAP elde

Sinir iletim çalışmalarında, duyu ve motor sinirle ilişkin yapısal ve işlevsel bilgiler elde edilir. Periferik bir

- Yazarların çalışma sonuçlarıyla ilgili herhangi bir çakışma ya da ilişki alanı yoktur.

- Illetişim adresi: Doç. Dr. Çağrı Mesut Temuçin, Hacettepe Üniversitesi Tıp Fakültesi, Nöroloji Anabilim Dalı, Ankara Tel: 0312 - 3051182 e-posta: ctemucin@hacettepe.edu.tr

- Geliș tarihi: 13 Ekim $2015 \quad$ Kabul tarihi: 13 Ekim 2015 
edilir. Motor iletim hızı da, bu iki uyarım noktası arasındaki mesafenin, distal BKAP latansının proksimal BKAP latansından çıkarılması ile elde edilen zamana bölünmesi ile hesaplanır. Böylece, sinir kas kavşağında geçen zaman bertaraf edilerek, sadece iki uyarım noktası arasında kalan motor sinir liflerinin hızını gösteren bir değer elde edilir. Diğer yandan, motor sinirlerde distal BKAP latansı, ek olarak, sinirin en distal bölgesindeki iletim hızı ile ilgili dolaylı bir bilgi verir. Bu bilgi, özellikle distal tuzak nöropatilerinde önemlidir. Ayrıca, motor sinirlerin, ön boynuz motor nörondan kasa kadar daha proksimal bölümlerini de içeren iletim zamanı, $\mathrm{F}$ dalgası çalışmaları ile elde edilen minimum $\mathrm{F}$ dalga latansı yoluyla, dolaylı olarak değerlendirilebilmektedir. Mikst sinir iletim çalışmasında ise, bir periferik sinirin motor ve duyu lifleri birlikte uyarılarak, aynı sinir üzerinden birleşik sinir aksiyon potansiyeli (BSAP) kaydedilir. Mikst sinir çalışmaları, BSAP motor liflere ait potansiyelleri içerse de, bundan daha çok, duyu sinirlerinin rutin inceleme sırasında değerlendirilemeyen daha proksimal bölümleri ile ilgili dolaylı bilgi edinmek için kullanılır. İletim hızları, distal ve $F$ dalga latansları, sinirlerin temel olarak miyelin kılıfi; BKAP ve DSAP genlikleri ise, akson sayısı ile ilgili bilgi vermektedir. Yaygın demiyelinizasyon ile giden patolojilerde, duyu ve motor sinir iletim hızlarında yaygın yavaşlama ile distal ve $\mathrm{F}$ dalgası latanslarında uzama gözlenirken, aksonal patolojilerde DSAP ve BKAP genliklerinde düşüş izlenir.

Özellikle tuzak nöropatilerde, bu rutin motor sinir iletim çalışmalarına ek olarak, motor sinirlerin farklı segmentlerinin proksimal ve distalden uyarılması ile, arada kalan segmentlerdeki fokal iletimi ile ilgili bilgi de elde edilebilmektedir. Segmental demiyelinizasyon durumunda, yani sinirin miyelin kılıfının homojen olarak etkilenmesinden ziyade kompresyon gibi sinirin belli bir bölümünde miyelin hasarının oluşması durumunda, bu segmental çalışmalarda, bazı özgün elektrofizyolojik bulgular ortaya çıkar. Tuzak nöropatilerin tanısında, segmental demiyelinizasyon bulgusu olarak, iletim hızlarında segmental yavaşlama ve motor iletim bloğu çok değerlidir. Motor iletim bloğu, bir sinirin aksonları sağlam iken, bazı liflerinde fokal miyelin kaybı olması nedeniyle, lezyonun proksimalinden uyarım ile elde edilen BKAP genliklerinin, lezyonun distalinden uyarım ile elde edilen BKAP genliğine göre daha düşük olarak elde edilmesidir. Nedeni, distal uyarım lezyonun distalinden gerçekleştirildiği için tüm liflere ait aksiyon potansiyelleri kasa ulaşabilirken, proksimal uyarımda, bazı liflerin miyelin kaybı nedeniyle aksiyon potansiyelinin kasa ulaşamaması sonucu, proksimal BKAP genliğinde düşüştür. Motor iletim bloğunun klinik karşılığ, ciddi kas güçsüzlüğüdür. Bu segmental bulguların daha hassas olarak ortaya çıkartılabilmesi için, sinir 2 $\mathrm{cm}$ gibi daha kısa segmentlerde uyarılarak, komşu iki segment arasındaki iletim hızı ve BKAP genliği farklılıkları incelenebilir. Santimleme yöntemi olarak isimlendirilen bu çalışmalar ile, kompresyon bölgesi daha hassas olarak gösterilebilir.

\section{İğne EMG İncelemeleri}

İ̆ne EMG çalışmalarında, motor üniteler değerlendirilir. Kas içine yerleştirilen iğne kayıt elektrotu ile, istirahat, hafif istemli kası ve tam kası sırasında değerlendirmeler yapılır.

İstirahat sırasında, son plak bölgesinden kaynaklanan bazı fizyolojik spontan aktiviteler dışında, her hangi bir elektriksel aktivite gözlenmemesi gerekir. Incelenen kasta, nörojenik (kök veya ön boynuz hasarı, pleksus lezyonu, periferik sinir hasarı gibi) patolojiler sonucu denervasyon gelişmesi durumunda ise, fibrilasyon potansiyelleri ve pozitif keskin dalgalar şeklinde anormal spontan aktiviteler izlenir. Bu aktiviteler, denerve olmuş kas liflerinin membran elektriksel özelliklerinin değişmesi nedeni ile, ortaya çıkan spontan elektriksel salınımları yansıtır.

Hafif istemli kası sırasında ise, belli sayıda motor ünite aksiyon potansiyelleri (MÜAP) değerlendirilir. Sağlıklı bir kasta MÜAP'ların, belli genlik, süre ve faz sayısına sahip olması gerekir. Denervasyon sonrası reinnervasyonun gelişmesi durumunda, kollateral filizlenme ile sağlam motor üniteler, denerve olmuş kas liflerinin de reinnervasyonunu sağlar. Bu durumda, MÜAP'ların genlik, süre ve polifazilerinde artış izlenir. Bu bulgular, incelenen kasta kronik denervasyon ve reinnervasyon sürecini gösterir. Reinnerve olan kas liflerinde, zamanla anormal spontan aktiviteler kaybolur.

İğne EMG çalışmasında, son olarak, istemli kasının giderek arttırılması ve tam kası sırasında motor ünitelerin katılım paterni incelenir. Kuvvetin arttırılması ile, iğne elektrod daha fazla sayıda MÜAP kaydeder. Motor iletim bloğu veya aksonal kayıp durumlarında, bu katılım paterninde azalma gözlenir.

\section{SiNIR ILETIM VE IĞNE EMG ÇALIŞMALARININ TUZAK NÖROPATILERDEKI YERi}

ENMG incelemesini yönlendirmek açısından, hekimlerin, klinik muayene, ön tanılar ve ek incelemeden ne istendiğini belirtmeleri önemlidir. Yukarıda kısaca özetlenen elektrofizyolojik çalışmalar ile, tuzak nöropatilerde; lezyonun varlığı, sinirin hangi bölümün etkilendiği (akson veya miyelin), lezyonun şiddeti, lokalizasyonu, zaman içindeki seyri, tedaviye yanıtı ve ayırıcı tanı konusunda bilgiler elde edilebilir. Tuzak nöropatiler esas 
olarak segmental demiyelinizasyon ile seyretse de, buna sekonder aksonal hasar da eşlik edebilir.

Sinir iletim çalışmalarında, sadece kompresyon gerçekleşen tuzak bölgesini içeren sinir segmentinde motor ve duyu iletim hızında yavaşlama ile motor iletim bloğu şeklinde fokal bulguların izlenmesi, lezyonun demiyelinizan özellikte olduğunun göstergesidir. Kompresyon bölgesinin distalinde veya proksimalinde kalan sinir bölümlerinde motor ve duyu iletim hızı, distal latans ile BKAP ve DSAP genliklerinin normal olması ile birlikte iğne EMG çalışmasında denervasyon bulgularının izlenmemesi, yine lezyonun demiyelinizasyon ile sınırlı olduğunu destekler. Bu durum, özellikle motor kaybın ciddi olmasına karşın, prognozun daha iyi olabileceğinin göstergesidir. Proksimal tuzak nöropatilerde, belirgin duyusal semptomlar olmasına rağmen duyu iletim çalışmalarının normal olması, bu çalışmaların kompresyonun distalinde, sağlam sinir segmentlerinde gerçekleştiriliyor olması nedeniyledir. Sinir iletim ve iğne EMG çalışmalarında distal BKAP ve DSAP genliklerinde düşüş şeklinde bulgular ise aksine, Wallerian dejenerasyonun distale ilerlemesi ile sekonder aksonal hasarın geliştiğinin ve prognoz açısından daha olumsuz bir süreç olacağının göstergesidir. Tüm bu bulgular, gerek lezyonun klinik takibinde gerekse cerrahi girişimim planlanmasında ve etkinliğini değerlendirilmesinde önemlidir. Klinik takipte veya cerrahi girişim sonrası gerçekleştirilen ENMG incelemelerinde, önceki ENMG incelemesi ile karşılaştırılarak düzelmenin veya kötüleşmenin objektif olarak gösterilmesine yardımcı olur. Özellikle motor iletim bloklarında düzelme, klinik düzelme ile yakından ilişkilidir.

ENMG incelemesinin zamanlaması önemlidir. Her zaman için, elde edilen elektrofizyolojik bulgular, incelemenin lezyonun gelişmesinden ne kadar sonra gerçekleştirildiği göz önüne alınarak yorumlanmalıdır. Bulgular, lezyonun oluş zamanı ile ilgili olarak, kronolojik bir sıra ile ortaya çıkar. Tuzak nöropatilerde olduğu üzere, segmental demiyelinizasyon ile seyreden patolojilerde en erken ENMG bulgusu, iğne EMG'de katılım paterninde azalma ile sinir iletim çalışmalarında motor iletim bloğu ve $F$ dalgası değişiklikleridir. Aksonal kayba yol açmadığı sürece, lezyonun distalinde gerçekleştirilen duyu ve motor sinir iletim çalışmaları normal kalır. Aksonal patolojilerde ise, iğne EMG'de akut dönemde en erken, yine katılım paterninde azalma izlenirken, günler içinde sinir iletim çalışmalarında DSAP ve BKAP genliklerinde lezyonun şiddeti ile orantılı düşüşler gözlenir; günler-haftalar içinde ise, iğne EMG'de anormal spontan aktiviteler şeklinde akut denervasyon bulguları gözlenir. Öte yandan, subakutkronik dönemde reinnervasyon gelişmesi durumunda, daha önce tanımlanan kronik MÜAAP değişiklikleri ortaya çıkar. ENMG incelemesindeki tüm bu anormal bulguların şiddetinin, lezyonun şiddeti ile doğrudan ilgili olacağı akılda tutulmalıdır. Bazen, hafif olgularda, ancak sağlam ekstremite ile karşılaştırıldığında ortaya çıkarılabilen patolojiler saptanabilmektedir.

\section{Ayırıcı Tanı}

Elektrofizyolojik ayırıcı tanı, duyu ve motor sinir iletim çalışmalarında hangi sinirlerin ve hangi segmentlerinin etkilendiğine, etkilenmenin esas olarak demiyelinizan $\mathrm{mı}$ aksonal mı olduğuna ve iğne EMG bulgularının kaslar arasındaki dağılımına, yaygınlığına dayanır.

Periferik sinirler, tuzak bölgeleri dışında, travma, infiltrasyon, vaskülit gibi nedenler ile de hasara uğrayabilir. Tedavi ve takip açısından farklılıklar gösteren bu durumların, tuzak nöropatilerden ENMG ile ayrı$\mathrm{m}$ önemlidir. Lezyonun distalinde kalan periferik sinir bölümünün etkilendiği bu durumlarda, esas olarak aksonal tipte ENMG bulguları gözlenirken; tuzak nöropatilerde, sadece tuzak bölgelerinde segmental demiyelinizasyon ve distalinde kısmen sekonder aksonal bulgularının izlenmesi oldukça değerlidir.

Diyabet gibi hastalıklarda, tuzak nöropatilere eğilimin arttığı bilinmektedir. Bu gibi durumlarda, altta yatan aksonal polinöropatinin ENMG ile gösterilmesi önemlidir. Duyu sinirlerinden DSAP alınamaması, tuzak nöropatinin ağır şiddette olduğunu gösterebileceği gibi, altta yatan aksonal bir polinöropatiye de bağlı olabilir. Bu nedenle, sinir iletim çalışmasında diğer sinirlerin değerlendirilmesi önem kazanır. Demiyelinizasyon ile giden nöropatilerde (Guillain-Barre sendromu, kronik inflamatuvar demiyelinizan polinöropati, multifokal motor nöropati) ise, tuzak nöropatilerde olduğu gibi, motor iletim blokları gözlenebilmektedir. Ancak, bu blokların tuzak bölgeleri dışında gözlenmesi ve yaygın demiyelinizasyon bulguları ile elektrofizyolojik tanı konur. Ailesel basınca duyarlılık nöropatisi olarak isimlendiren kalıtımsal bir hastalıkta, çok sayıda tuzak bölgesinde sinir etkilenimi ortaya çıkmaktadır. Kendiliğinden düzelmenin ve tekrarlamanın gözlenebildiği, cerrahi yaklaşımın da oldukça tartışmalı olduğu bu durumun tanınması önemlidir. Tuzak nöropati açısından, yaş, cinsiyet, meslek, sistemik hastalık riski taşımayan kişilerde, çok sayıda tuzaklanma bölgesinde sinir tutuluşunun olması uyarıcı olmaktadır.

Düşük ayak, düşük el, el ve ön kol kaslarında atrofi ve kuvvet kaybı gibi fokal motor kayıplar, radikülopatilerde veya nadiren de olsa daha yaygın ön boynuz motor nöron hastalıklarının başlangıç döneminde de gözlenebilir. Bu durumların tuzak nöropatilerden ayrımı yine önemlidir. Kök veya ön boynuz motor nöron hastalıklarında duyu sinir iletim çalışmaları 
korunduğu halde, özellikle sürecin ilerlemesi ile, motor sinir iletim çalışmalarında anormallikler saptanabilir. Radikülopatilerde belirgin duyusal semptomlara rağmen, duyu sinirlerinin hücre gövdesi kök lezyonunu distalinde kaldığı için, distalde gerçekleştirilen rutin sinir iletim çalışmaları normal olarak bulunur. Motor iletim hızları büyük ölçüde normal sınırlar içerisinde iken; BKAP genliklerinde düşme, en belirgin özelliktir. Diğer yandan, radikülopati ve motor nöron hastalığı tanısı, esas olarak iğne EMG çalışmasında dayanır. Aynı kökten, ancak farklı sinirlerle innerve kaslarda, segmental dağılım gösteren nörojenik iğne EMG bulgularının paraspinal kaslarda da gözlenmesi, kök lezyonu lehinedir. Ekstremite kaslarının yanı sıra kraniyal sinir innervasyonlu veya torakal paraspinal kaslarda da nörojenik değişikliklerin gözlenmesi ise, akla motor nöron hastalıklarını getirir. Son olarak, brakiyal pleksusun aynı trunkusundan ancak farklı periferik sinirlerce innerve kasların değerlendirilmesi, saptanan bulguların brakiyal pleksus lezyonundan ayırt edilmesi için gereklidir.

\section{ÜST EKSTREMITELERDE TUZAK NÖROPATI}

Rutin incelemelerde, median ve ulnar sinir duyu ve motor sinir iletim çalışmaları gerçekleştirilir. Median sinir motor iletim çalışmalarında, sinir el bileği ve antekübital fossadan uyarılıp abduktor pollisis brevis (APB) kasından kayıt alınırken, ulnar motor sinir ise el bileği, dirsek altı ve dirsek üstünden uyarılarak abduktor dijiti mini (ADM) kasından kayıtla gerçekleştirilir. İletim çalışmaları; median duyu sinirler için 1.-3. parmak - bilek ve avuç içi - bilek segmentlerinde, ulnar duyu sinir için ise 5. parmak-bilek segmentleri arasında gerçekleştirilir.

\section{Median Sinir Tuzak Nöropatileri}

\section{Karpal Tünel Sendromu (KTS)}

Sinir iletimi çalışmaları: KTS'nin patofizyolojisi demiyelinizasyon ile ilişkilidir. Demiyelinizasyon şiddetinin ağırlığına göre, sekonder aksonal hasar eşlik edebilir. Rutin sinir iletimi çalışmasında median sinirin karpal tünelde kompresyonuna bağlı gelişen demiyelinizasyonun göstergesi, duyu iletimlerinde yavaşlama ve motor distal latansta uzamadır. Distalde iletim bloğu olması durumunda, BKAP genliklerinde düşüş de gözlenebilir. Kompresyon sekonder aksonal kayba yol açarsa, bu bulgulara median duyu DSAP ve motor sinir BKAP genliklerinde azalma eşlik edebilir.

Hafif şeklinde, median sinir parmak - bilek ve avuç içi - bilek segmentlerinde, duyu iletim hızlarında yavaşlama izlenir. Bu amaçla, genellikle 2. parmak - bilek ve avuç içi - bilek segmentleri çalışılmakla birlikte, median sinir duyu dalından innerve diğer parmakların çalışılması, testin duyarlılığını yükseltir. Motor iletim çalışmalarında anormal bulgular, patolojinin seyri sırasında daha ileri dönemlerde ortaya çıkmaktadır. Tipik bulgu, median sinirin el bileğinden (karpal tünelin proksimalinden) elektriksel uyarımı ile elde edilen distal latansta uzamadır. Motor lifler karpal tünelin içinden geçerek APB kasını innerve ettiğinden, karpal tünel içinde baskıya uğramaları nedeniyle, sinir aksiyon potansiyelinin APB kasına ulaşma zamanı olan distal latansta gecikme ortaya çıkar. Ön kol segmenti motor iletim çalışmaları ise, karpal tünelin proksimalinde gerçekleştirildiğinden normal olarak kalır. Bu bulgu, KTS'nin, median sinirin daha proksimal hasarlarından ayrımında önemlidir.

Sinir iletimi çalışmaları normal olmasına rağmen, hastaların \%15-20'sinde klinik ve muayene bulguları ile KTS teşhisi düşünülebilir. Bu hasta grubunda, daha hassas elektrofizyolojik incelemeler yapılabilmektedir. Bu çalışmalarda, etkilendiği düşünülen median sinirin duyu iletim hızları ile motor distal latansı, bir başka sinir ile karşılaştırılmaktadır. Bu amaçla,

- etkilenen elde median sinir duyu iletim hızının, ulnar ve süperfisiyel radyal duyu iletim hızları ile karşılaştırılması,

- etkilenen elde median sinirin motor distal latansının, ulnar sinir distal latansı ile karşılaştırılması,

- etkilenen elde median sinir motor sinir distal latansının ve duyu iletim hızının karşı taraf median sinir ile karşılaştırılması çalışmaları gerçekleştirilebilmektedir.

Bu karşılaştırma testleri klinik rutin uygulamalarda nadiren kullanılmaktadır. Karşılaştırılan sinirlerde asemptomatik patolojilerin bulunma olasılığı, bu testlerin kullanımını sınırlamaktadır.

iğne EMG incelemesi: Iğne EMG incelemesi, tanıya katkıdan çok, hastalığın derecesi ve şiddeti hakkında bilgi verir. KTS'nin ileri dönemlerinde distal liflerin sekonder aksonal dejenerasyonu ile, tenar kaslarda nörojenik değişiklikler izlenirken, karpal tünelin proksimalinde kalan median sinir innervasyonlu kaslar normaldir.

ENMG'de KTS kriterleri:

1. Hafif şiddette KTS: Median sinir duyu iletim hızlarında yavaşlama.

2. Orta şiddette KTS: Hafif KTS bulgularına ek olarak, median motor sinir distal latansında uzama.

3. İleri derecede KTS: Median sinir DSAP elde edilememesi; motor sinir distal latansında uzama.

4. Çok ağır şiddette KTS: Median sinir DSAP elde edilememesi; median sinir distal latansında uzama; BKAP genliğinde azalma. APB kası iğne EMG'de nörojenik bulgular. 
Yakınmanın olduğu elde KTS saptanması durumun$\mathrm{da}$, asemptomatik olsa bile, diğer elde de median sinir iletim çalışmalarının gerçekleştirilmesi gerekir. Sinir iletim çalışmaları, kimi durumlarda, altta yatan diyabetik aksonal polinöropatinin saptanması konusunda da yardımcı olmaktadır. KTS değerlendirilmesi sırasında, Martin-Gruber anastomozu gibi çeşitli anatomik varyasyonlar yanıltıcı olabilmektedir. İnceleme sırasında median ve ulnar sinirlerde beklenmedik bulguların saptanması, bu konuda uyarıcı olabilmektedir.

\section{Proksimal Median Sinir Nöropatileri}

Struther bağı tuzaklanması: Humerusun distal mediyal kısmında, suprakondiler çıkıntının üstünde bulunan struther bağı fibröz bandının altında median sinir tuzaklanmasına bağlıdır. Sinir iletim çalışmalarında, tuzaklanma bölgesinin proksimalinin uyarımı ile, distal uyarıma göre düşük genlikli BKAP (motor iletim bloğu) ve bu segmentte motor iletim hızında yavaşlama izlenebilir. Aksonal hasar gelişmiş ise, hasarın şiddeti ile orantılı olarak, median sinir DSAP ve distal BKAP genliklerinde düşüş izlenebilir. İğne EMG'de, pronator teres kası dahil olmak üzere, median innervasyonlu tüm kaslarda nörojenik değişiklikler izlenir.

Pronator teres sendromu: Median sinirin, pronator teres kaslarının humeral ve ulnar başları arasından geçerken tuzaklanmasına bağlıdır. Sinir iletim çalışmalarında kompresyonun belirgin olması durumunda, median sinir ön kol segmenti motor iletim hızında yavaşlama veya motor iletim bloğu izlenebilir. Ancak, bu çok sık rastlanan bir bulgu değildir. Aksonal kaybın gelişmesi durumunda ise, median sinir distal BKAP ve DSAP genliklerinde düşme gözlenir. Tanıda esas olarak, iğne EMG'de, median sinir innervasyonlu kaslarda lezyonu lokalize ettirici bulguların izlenmesi önemlidir. Pronator teres kası iğne EMG incelemesi büyük oranda normal olarak saptanırken, diğer median sinir innervasyonlu ön kol kaslarında (fleksör karpi radyalis, fleksör dijitorum profundus ve süperfisiyalis (1-3. parmaklar), fleksör pollisis longus, pronator kuadratus) nörojenik değişiklikler izlenebilir.

Anterior interosseöz sendromu: Hastalar, ön kolda ağrı ve daha akut başlangıçlı bir kas zafiyeti hissederler. Başparmak, işaret parmağı ve orta parmağı ilgilendiren kas güçsüzlügü mevcuttur. Median sinirin bu distal anterior interosseöz dalının duyu innervasyonu yoktur. Dolayısı ile, median sinir duyu iletim çalışmaları normal sınırlar içerisindedir. Yine, APB kasında gerçekleştirilen rutin motor sinir iletim çalışması normaldir. Anterior interosseöz sinirin innerve ettiği pronator kuadratus kasında, motor iletim çalışmalarında bozukluklar saptanabilir. Ancak, en tanısal bulgu, pronator teres ve fleksör karpi radyalis kası iğne EMG incelemesi normal iken, fleksör dijitorum profundus (1-3. parmaklar), fleksör pollisis longus ve pronator kuadratus kaslarında nörojenik değişikliklerin saptanmasıdır.

\section{Ulnar Sinir Tuzak Nöropatileri}

\section{Dirsek Hizasında Ulnar Sinir Tuzak Nöropatileri}

Ulnar sinirin dirsek hizası nöropatileri, Kübital Tünel Sendromu ve Tardy Ulnar Palsy'dir. Her iki lezyonda da, rutin sinir iletim çalışmaları ve iğne EMG bulguları benzer özellikler gösterir. Motor sinir iletiminde, dirsek üstü - dirsek altı segmenti sinir iletim hızı normalin altında veya dirsek altı - el bileği segmenti hızına göre düşüktür. Dirsek segmentinde motor iletim bloğunun gözlenmesi ise oldukça tanısaldır. Distalde çalışılan ulnar duyu iletim çalışmaları, aksonal kayıp geliş̧medikçe normaldir. Bu iki nöropatinin ayrımı ve lezyonun dirsekte lokalizasyonu için, ulnar sinir, mediyal epikondilin proksimal ve distalinde, $2 \mathrm{~cm}$ aralıklarla farklı noktalardan uyarılır. Iki santimlik segmentlerde elde edilen BKAP genlik ve latansları karşılaştırılır (santimleme yöntemi). Herhangi bir segmentte latansta uzama veya genlikte düşüş, lezyonu o segmente lokalize ettirir. Özellikle C8 innervasyonlu, ancak median sinir innervasyonlu APB kasının incelenmesi, C8 kök lezyonundan ayırt edilmesini sağlayabilir. İğne EMG çalışmasında, nörojenik değişiklikler en sık abduktor dijiti mini ve I. dorsal interosseöz kaslarnda izlenirken, fleksör karpi ulnaris (FKU) ve fleksör dijitorum profundus (FDP) kasları normal olarak bulunabilir. Dolayısı ile, FKU ve FDP kaslarının normal bulunması, dirsek hizasında ulnar nöropati tanısını dışlamaz. Elektrofizyolojik incelemeler esnasında, Martin-Gruber anastomozu gibi, ulnar, median sinir anatomik varyasyonları akılda tutulmalı ve gerçek dirsek segmenti blok varlığından ayırılmalıdır.

\section{Kübital Tünel Sendromu}

Ulnar tuzak nöropatilerin en sık görülenidir. Kübital tünel sendromunda, motor lif tutulumu duyusala kıyasla daha belirgindir ve motor ileti çalışmaları daha yol göstericidir. Tipik bulguları; santimleme yöntemi ile, dirsek segmentinde, mediyal epikondilin distalindeki segmentlerde, motor sinir iletim hızında fokal yavaşlama ve bu segmentte motor iletim bloğunun gösterilmesidir.

\section{Tardy Ulnar Palsy}

Kübital tünel sendromundan sonra ikinci sıklıkta gözlenen tuzak nöropatisidir. Ulnar sinir, humerus mediyal epikondili arasındaki oluktan ilerlerken, burada yer alan fleksör karpi ulnaris ve olekranon arasındaki fibröz kemerin proksimal kenarında kompresyona uğrar. Tipik bulguları, santimleme yöntemi ile, dirsek 
segmentinde, mediyal epikondilin yaklaşık $2 \mathrm{~cm}$ proksimalinde, motor sinir iletim hızında fokal yavaşlama ve bu segmentte motor iletim bloğunun gösterilmesidir.

\section{Guyon Kanalı Tuzaklanması}

Bilek seviyesinde, pisiform kemikle hamatum arasında ulnar sinirin sıkışması ile gelişir. Sinir lezyonu dört gruba ayrılarak incelenir. Lezyon lokalizasyonu elektrofizyolojik bulgulara göre yapılabilir. Bu amaçla, ek olarak, I. dorsal interosseöz kastan motor iletim ve dorsal kutanöz duyu iletim çalışmaları yapılır. Dorsal kutanöz sinir, Guyon kanalına girmeden önce ayrıldığı için, iletim çalışmalarının normal olması ile daha proksimal ulnar nöropatilerden ayrıma yardımcı olur.

Tip 1: Guyon kanalının içinde veya hemen girişinde ortaya çıkan nöropatidir. ADM ve I. dorsal interosseöz kasların distal latansı uzamıştır; 5. parmak - el bileği duyu iletim çalışması anormaldir.

Tip 2: Guyon kanalı veya distalinde gelişen nöropatidir. ADM ve I. dorsal interosseöz kasların distal latansı uzamıştır; 5. parmak - el bileği duyu iletim çalışması ise normaldir.

Tip 3: Hipotenar kaslara giden dal ayrıldıktan sonra gelişen lezyondur. ADM kası distal latansı normal, I. dorsal interosseöz kasın distal latansı uzamış, 5. parmak - el bileği duyu iletim çalışması normaldir.

Tip 4: Guyon kanalının distalinde duyusal dalın etkilendiği formdur. ADM ve I. dorsal interosseöz kasların distal latansı normal, 5. parmak - el bileği duyu iletim çalışması ise anormaldir.

iğne EMG: Fleksör karpi ulnaris ve fleksör dijitorum profundus kasları normalken, ADM ve I. dorsal interosseöz kaslarnda denervasyon bulguları vardır.

\section{Radyal Sinir Tuzaklanması}

Sinir iletim çalışmalarında, etkilenen tarafta median ve ulnar sinir iletim çalışmaları ile her iki tarafta karşılaştırmaya olanak vermesi için, radyal motor ve süperfisiyel radyal duyu sinir iletim çalışmaları gerçekleştirilir. Radyal motor iletim çalışması, ekstansör indisis proprius kasından kayıtla, radyal sinirin ön kol, dirsek, spiral oluk distali ve proksimalinden uyarılarak gerçekleştirilir.

\section{Radyal Sinir Spiral Oluk Tuzaklanması}

"Cumartesi gecesi felci" olarak da isimlendirilen bu tablo, spiral oluk düzeyindeki dış basıya bağlı radyal sinirin hasarlanmasına bağlıdır. Sinir iletim çalışmasında, ekstansör indisis proprius kasından kayıtla gerçekleştirilen motor iletim çalışmaları sırasında, spiral oluk proksimalinden uyarım ile elde edilen BKAP genliğinin, distal uyarımlar ile normal sınırlarda elde edilen BKAP genliklerine göre belirgin derecede düşük olması (motor iletim bloğu), en tipik bulgusudur. Yine, spiral oluk distali ve proksimali arası segmentte ölçülen, motor iletim hızında yavaşlama izlenir. Sadece demiyelinizasyona yol açan durumlarda, süperfisiyel radyal sinir duyu iletim ve ön kol motor iletim çalışmaları kompresyonun distalinde gerçekleştirildiğinde etkilenmez. Kompresyonun sekonder aksonal hasara yol açması durumunda ise, distal BKAP ve süperfisiyel radyal sinir DSAP genliklerinde de düşüşler izlenir.

iğne EMG incelemesi: Triseps kası iğne EMG'si normaldir. Brakiyoradyalis kası dahil diğer tüm radyal innervasyonlu kaslarda, EMG'de nörojenik değişiklikler mevcuttur.

\section{Posterior Interosseöz Sendromu}

Posterior interosseöz sinir, radyal sinirin saf motor dalıdır. Radyal sinir duyu iletim çalışmaları normaldir. Ekstansör indisis proprius kasından elde edilen motor distal latansta ise uzama izlenebilir. İğne EMG incelemesinde, triseps, brakiyoradyalis ve ekstansör karpi radyalis kasları normalken, ekstansör dijitorum komünis, ekstansör karpi ulnaris ve ekstansör indisis proprius gibi bu sinirle innerve kaslarda, nörojenik değişiklikler izlenir.

\section{ALT EKSTREMITELERDE TUZAK NÖROPATILER}

Alt ekstremitelerin rutin sinir iletim çalışmalarında, posterior tibial ve peroneal sinir motor ve sural sinir duyu iletim çalışmaları gerçekleştirilir. Bu çalışmalar, olası bir tuzak nöropatisinin diğer sinir lezyonlarından ayrım için gereklidir.

\section{Lateral Femoral Kutanöz Sinir}

Lateral femoral kutanöz sinir tuzaklanması, diğer adıyla "meraljiya parestetika" inguinal bağ seviyesinde gerçekleşir. Duyusal semptomların yerleşim bölgesi nedeniyle, daha çok L2-4 radikülopatiler ile karıştırılabilir. ENMG'de, iki taraflı olarak, lateral kutanöz femoral sinir duyu iletimi çalışılıp karşılaştırılabilir. Hastaların çoğunda, patolojik tarafta yanıt elde edilemez. Az bir kısmında ise, sağlam tarafla karşılaştıııldığında, latans uzamış olarak bulunur. Ancak bu çalışmalar, sinirin seyri nedeniyle, iğne kayıt elektrotlar kullanılarak "sinire yakın kayıt" tekniği gibi oldukça güç teknikler ile gerçekleştirilebilmekte olup, klinik kullanımları sınırlıdır. Yine, dermatomal somatosensoriyel potansiyel çalışmasının daha hassas olduğu belirtilmektedir. İğne 
EMG incelemesi, esas olarak L2-4 kök lezyonundan ayrımında yardımcıdır. Lateral femoral kutanöz sinirin motor dalı olmadığı için, iğne EMG'nin normal olması beklenirken, kök lezyonlarında iliopsoas veya kuadriseps kas grubunda nörojenik değişiklikler saptanması, ayırıcı tanıyı sağlar.

\section{Piriformis Sendromu}

Siyatik sinirin, siyatik çentiği terk ettikten sonra priformis kasının altında geçerken tuzaklanmasına bağlıdır. Oldukça nadir bu durumda, rutin sinir iletim çalışmaları büyük oranda normaldir. Kalça ekleminin çeşitli manevraları sırasında, $\mathrm{H}$ refleksi çalışııması gibi özel testlerle, bazı olgularda bulgu saptanabilmektedir. Elektrofizyolojik incelemeler, daha çok, ayırt edici tanı için yardımcı olmaktadır.

\section{Tarsal Tünel Sendromu}

Mediyal ve lateral plantar sinirin veya sadece bir tanesinin tarsal tünelde kompresyonu ile gelişir. ilk kullanılan ve en pratik yöntem, mediyal plantar sinir için abduktor hallusis longus, lateral plantar sinir için ise abduktor dijiti kuinti pedis kaslarından distal motor latansın değerlendirilmesidir. Posterior tibial sinirin ayak bileğinden uyarılması ile bu kaslardan elde edilen distal latanslarda, sağlam tarafa göre uzama bir kompresyonu desteklese de, hassasiyetleri düşüktür. Mediyal ve lateral plantar duyu siniri iletim çalışılması ise, çok daha hassas olmakla birlikte, yüzeyel elektrodlar ile saptanan DSAP genliklerinin normal kişilerde çok düşük olması ve özellikle yaşlı kişilerde normalde de elde etmek güç olduğu için, iğne elektrodlarla sinire yakın uyarım tekniği ile kayıtlama tanısal hassasiyeti arttırır. Ancak, bu teknik daha güç ve zaman gerektirdiğinden, rutin uygulamada çoğu zaman tercih edilmemektedir. İ̆ne EMG çalışmasında, abduktor hallusis longus ve abduktor dijiti kuinti pedis kaslarında nörojenik değişiklikler izlenebilir. İğne EMG çalışmalarında, yakınmaları LS-S1 kök lezyonundan ayırt edici olan bulguların saptanması da önemlidir. Daha distalde, dijital sinirler ile ilgili ile nöropatiler (Morton nöroması), ancak dijital sinirlerde sinire yakın iğne elektrodla kayıtlamaya dayanan zaman alıcı ve oldukça güç tekniklerle çalışılabilmektedir.

\section{Peroneal Sinir Tuzaklanması}

Sinir iletimi çalışmaları: Düşük ayaklı ve peroneal nöropati şüphesi olan hastalarda, rutin çalışmalara ek olarak, süperfisiyel peroneal sinir duyu iletim çalışmaları gerçekleştirilir. Peroneal motor sinir iletim çalışması ise, ekstansör dijitorum brevis kasından kayıt alınarak, sinirin ayak bileği, diz altı ve diz üstünden uyarılması ile gerçekleştirilir. Peroneal motor ve süperfisiyel peroneal duyu iletim çalışmaları, karşılaştırmaya olanak vermesi için, sağlam tarafta da gerçekleştirilir.

Fibula başındaki kompresyona bağlı demiyelinize lezyonlarda, diz üstü - diz altı segmentleri arasında peroneal sinir motor iletim hızında yavaşlama gözlenirken, diz altı - ayak bileği arasındaki segmentte iletim hızı normal sınırlar içerisindedir. Diz üstü - diz altı segmentinde motor iletim hızında, diz altı - ayak bileği segmentine göre $10 \mathrm{~m} / \mathrm{sn}$ 'den fazla bir yavaşlamanın olması da anlamlıdır. Diğer yandan, diz üstü uyarım ile BKAP genliğinde diz altı ve ayak bileği uyarımına göre belirgin düşüklüğün olması (motor iletim bloğu), tanısal değerdedir. Lezyonun kaput fibulaya lokalize edilmesini sağlar. Santimleme yöntemi kullanılarak, peroneal motor sinirin fibula başı etrafinda daha kısa aralıklarla $(2 \mathrm{~cm})$ uyarılması, lezyonun daha da hassas lokalizasyonunu sağlayabilir. Sadece segmental demiyelinizasyonun varlığında motor distal BKAP ve süperfisiyel peroneal DSAP genlikleri normaldir. Aksonal hasar varsa, motor iletim bloğunun yanı sıra BKAP ve DSAP genliklerinde de düşüşler gözlenir. Posterior tibial motor ve sural duyu iletim çalışmalarının normal sınırlar içerisinde olması, peroneal sinir lezyonunu siyatik sinir veya lumbo-sakral pleksusu lezyonundan ayırt edilmesinde önemlidir.

iğne EMG incelemesi: İğne EMG, peroneal sinir lezyonunun lokalizasyonu, şiddeti ve daha önemlisi diğer olası tanıların (siyatik nöropati, radikülopati, pleksopati) dışlanması için önemlidir. Aksonal kayıplı hastalarda, peroneal sinir innervasyonlu kaslarda (tibialis anterior, peroneus longus, ekstansör dijiti brevis) nörojenik değişiklikler izlenir. Bu kaslarda anormal iğne EMG bulguları olduğunda, L5 innervasyonlu ancak farklı sinir ile innerve diğer kaslarda da, kök hastalıklarından ayrım için, iğne EMG incelemesi yapılmalıdır. Ancak posterior tibial sinir ile innerve tibialis posterior kası veya gluteal sinir ile innerve gluteus medius kasları ve L5 innervasyonlu paraspinal kasların incelemesi, L5 kökünden bu ayrımı sağlayabilir. Bu kasların tutulumu, peroneal sinir lezyonunu dışlayıp, L5 kök lezyonunu destekler. Biseps femorisin kısa başının incelenmesi ve patolojik bulunması ise, daha çok, siyatik sinir tutulumu lehinedir.

\section{KAYNAKLAR}

1. Oh SJ. Clinical electromyography -nerve conduction studies. J Neurol Sci 1985;69:117. CrossRef

2. Dumitru D, Amato A, Zwarts M. Electrodiagnostic Medicine 2nd Edition. Philadelphia, PA: Hanley and Belfus Medical Publishers, 2001.

3. StewartJD. Proximal median neuropathies: electromyographic and clinical correlation. Muscle Nerve 1993;16(3):321-2.

4. Campbell WW, Pridgeon RM, Sahni KS. Short segment incremental studies in the evaluation of ulnar neuropathy at the elbow. Muscle Nerve. 1992;15(9):1050-4. 